\title{
EREBEA
}

Revista de Humanidades y Ciencias Sociales

Núm. 9 (2019), pp. 223-252

ISSN: 0214-0691

http://dx.doi.org/10.33776/erebea.v9i0.3785

\section{PAisAjes COTIDIANOS Y PAISAJES EXCEPCIONALES EN CASTILla y LEÓN: ESTADO DE LA CUESTIÓN Y PROPUESTA PARA LA ELABORACIÓN DE UN REGISTRO DE PAISAJES DE INTERES PATRIMONIAL}

Eugenio Baraja Rodríguez
Universidad de Valladolid

Daniel Herrero Luque Universidad de Burgos

Marta Martínez Arnáiz Universidad de Burgos

Fernando Molinero Hernando

Universidad de Valladolid

RESUMEN

La entrada en vigor en Espańa del Convenio Europeo del Paisaje (CEP) ha permitido abrir interrogantes y dar respuestas a algunos problemas territoriales. Para disciplinas como la Geografía ha significado el reencuentro y la revisión de su forma de aproximación al espacio. Sin embargo, transcurridos once años desde su entrada en vigor, la aplicación del CEP está siendo muy desigual en las distintas comunidades autónomas españolas. Para algunas, el paisaje ha tenido gran valor; para otras, como Castilla y León, muy poco.

\section{Palabras Clave}

Paisaje y patrimonio; paisaje de interés patrimonial; paisaje cultural; Castilla y León; Convenio Europeo del Paisaje.

Fecha de recepción: 19 de noviembre de 2019 Fecha de aceptación: 5 de diciembre de 2019

\section{Abstract}

The entry into force in Spain of the European Landscape Convention (ELC) has allowed us to make questions and to propose answers to some territorial problems. For disciplines such as Geography it has meant the reassume of a way of approaching to the spatial knowledge. However, after eleven years working, the application of the CEP is being very unequal in the different Spanish autonomous communities. For some, the landscape has had great value; for others, such as Castilla y León, very little.

\section{KeYwords}

Landscape and heritage, landscape with heritage value, cultural landscape; Castilla y León, European Landscape Convention. 

i. Paisaje y patrimonio en el marco del convenio europeo del paisaje

Desde distintos planteamientos y con diferentes inquietudes, el paisaje ha venido ocupando un lugar cada vez más importante en los debates académicos, técnicos y políticos en la España de los últimos años. Su consideración en diferentes documentos internacionales, como la Convención de la UNESCO sobre Patrimonio Mundial, Cultural y Natural de 1972, la Carta Europea de Ordenación del Territorio (1983) y otros de menor rango (Zoido, 2009), culminó con la presentación, firma y entrada en vigor (2004) del Convenio Europeo del Paisaje (CEP). Este documento ha tenido la virtud de convertirse en un revulsivo para el estudio del paisaje, tanto por la consideración abierta del concepto que aporta en su artículo primero -"cualquier parte del territorio tal y como la percibe la población"-, como por el compromiso que adquieren los firmantes para identificarlos en todo su territorio, analizar sus rasgos y dinámicas, y calificarlos "teniendo en cuenta los valores particulares que les atribuyen las Partes y la población interesadas" (Art. 6. C). Se trata, sin lugar a dudas, de un documento de madurez teórica sobresaliente, de ahí que se presente tan aparentemente sencillo en su formulación como complejo en su aplicación. Esta es la razón que justifica, por un lado, la proliferación de aportaciones que, a distintas escalas y desde diferentes disciplinas, abundan en el estudio de la variedad y singularidad de los paisajes; no es de extrañar que, para el caso concreto de la Geografía, Nicolás Ortega destacara en su momento los beneficios que podría deparar ese reencuentro con un clásico objeto de estudio "tras un tiempo en el que muchos geógrafos consideraron que hablar del paisaje era poco menos que incurrir en un anacronismo y renunciar al debido rigor científico" (Ortega, 2010: 269). Pero también explica, por otro, la evidente dificultad que se observa en su comprensión integral, y en las reticencias y cautelas al abordar el tratamiento y gestión de un asunto que compromete a numerosas políticas con incidencia espacial, como la ordenación del territorio, el medio ambiente, el desarrollo de las actividades económicas o el patrimonio (Martínez y Molinero, 2019).

En todo caso, lejos de lo que parece razonable a instancias del CEP, que es conocer en profundidad el carácter de los distintos paisajes, no siempre se ha operado de esta forma. Es más, aunque el CEP enfatiza la idea de que todo territorio se expresa como paisaje y que este concierne tanto a los que "puedan considerarse excepcionales como a los paisajes cotidianos o degradados" (art. 2), 
lo cierto es que progresivamente se ha puesto el foco en los primeros, es decir, en aquellos a los que se les atribuyen valores excepcionales, hipostasiando, así, su dimensión patrimonial. Ortega Valcárcel ya hacía alusión a los cambios habidos en un concepto, el de patrimonio, que, limitado inicialmente al campo estético y encerrado en la obra de arte singular o en la excepcional de la naturaleza, evolucionó hasta abarcar al conjunto territorial, que, en tanto que construcción social, tiene un componente de historicidad: "La dimensión estética que comporta el territorio, en la medida en que conlleva una composición que se traduce en un paisaje determinado, supone, ya, la posibilidad del disfrute escénico, del uso lúdico contemplativo que sustenta, en tantos aspectos, el culto por lo natural y por el paisaje en la tradición cultural occidental" (Ortega, 1998). Es una forma de enfatizar la cualidad patrimonial inherente a todo paisaje, entendido como imagen proyectada y percibida del territorio y, por tanto, heredera de una forma de organización. Siendo su naturaleza evolutiva, convierte a la sociedad, en cada momento, en responsable de la gestión de ese legado. Gestión directamente vinculada a unos valores que no solo son diversos, sino también variables, "por la componente cultural y la temporalidad que los pondera y jerarquiza. Los cambios espaciales que el paisaje refleja son fruto de la permanente mutación sobre el espacio previo, bien por acción (intervención) o por inacción (abandono), que cada sociedad y su tiempo imprimen sobre el territorio que se habita, explota y conforma según las necesidades y criterios de ordenación” (Martínez y Molinero, 2019).

Por otro lado, el paisaje entronca con el derecho al disfrute de un entorno de calidad. De hecho, el CEP le atribuye un valor decisivo en la calidad de vida de los individuos que viven en sociedad; lo que abre nuevas perspectivas de intervención desde la reflexión, el respeto, la cautela, la planificación y, en su caso, la conservación de sus aspectos esenciales, en los paisajes ordinarios o cotidianos. De esta forma, y a diferencia de lo que actualmente ocurre, podríamos, emulando las palabras de Pisón, acantonar el deterioro y extender la protección a la mayor parte del territorio. Y esta ponderación también es válida para los paisajes "patrimoniales", visión intencionadamente más restrictiva con el objeto de enfatizar la excepcionalidad de algunos paisajes sobre el conjunto. La UNESCO se refiere a ellos como Paisajes Culturales, que define como "Lugares que combinan el trabajo de la naturaleza y el ser humano, y que son ilustrativos de la evolución de la sociedad humana y del uso del espacio a lo largo del tiempo, bajo la influencia de limitaciones físicas y/o oportunidades presentadas por el medio natural y de sucesivas fuerzas sociales, económicas y culturales" (Directrices de la UNESCO, 1992: párrafo 39). La UNESCO los sitúa en la categoría superior de bien cultural o de bien mixto, destacando su valor como contenedores de esencias físico-naturales y/o humanas-histórico-culturales, lo que entronca con la idea de la dimensión y funcionalidad simbólica del patrimonio que defiende 
Davallon (2006). Colocar el foco en la dimensión patrimonial del paisaje, ha justificado la creación de catálogos de paisajes sobresalientes y excepcionales que, por los valores únicos o representativos que se les asignan, pueden ser objeto de protección especial mediante planes específicos.

Sin embargo, que el paisaje sea una cualidad de todo el territorio -de cada territorio- y que el concepto de paisaje tenga un profundo calado cultural, no implica que todos los paisajes sean paisajes patrimoniales, ha señalado Rafael Mata (2015). En el mismo sentido, Ortega apuntaba que "la identificación cultural y, por consiguiente, su valoración como recurso, queda supeditada al grado de desarrollo cultural en la propia sociedad, que condiciona la sensibilidad ante este tipo de objeto cultural, y a la capacidad de intervención de los agentes públicos o privados como reveladores de dicho interés" (Ortega, 1998: 41). Solo después de este proceso de asimilación social, el paisaje adquiere esa dimensión patrimonial, es valorado como producto cultural y es susceptible de ser utilizado como recurso en las estrategias de desarrollo territorial. Algo de notable valor en amplios espacios rurales aquejados por la atonía demográfica y por la escasa diversificación funcional, como ocurre en buena parte de las regiones del interior de Castilla y León en particular.

En esta comunidad autónoma se constata la paradoja de que, siendo el patrimonio una de sus señas de identidad estatutariamente reconocidas y, consecuentemente, enfatizando el valor patrimonial (excepcional) de alguno de sus paisajes, no ha habido hasta el momento criterios institucionales claros, ni interés manifiesto para llevar a cabo uno de los primeros y primordiales principios del CEP: profundizar en el conocimiento de sus paisajes, identificándolos en todo su territorio. Por otro lado, el escaso calado social del concepto, unido a la despoblación, dejan su valoración y cualificación abierta a miradas ajenas, por lo que su autenticidad no pasa de ser parcial.

Este hecho, nos lleva a valorar, en primer lugar, el proceso de implantación normativa del CEP en Castilla y León, cuestión que permitirá comprender mejor las dificultades que se encuentran actualmente para una cabal identificación y cualificación de los paisajes de mayor relevancia patrimonial.

\section{Consideración administrativa y JURídica del paisaje en Castilla y León}

Como afirma Ortega, el territorio se constituye en recurso cultural en virtud de una valoración social, pero el reconocimiento social arranca de sectores muy minoritarios cuya acción debe ser potenciada desde instancias públicas por medio de la Ordenación del Territorio, cuyo papel puede ser decisivo en la identificación, definición y revalorización cultural de los territorios como recurso (Ortega, 1998: 47). En el mismo sentido, Martínez y Molinero indican que “...La valoración social del paisaje, entendido con esta perspectiva general e integradora, requiere 
un desarrollo normativo que lo respalde y que permita estructurar su ordenación y gestión. A partir del CEP y de las Recomendaciones del Comité de Ministros a los Estados miembro sobre las orientaciones para la aplicación del Convenio (2008), los países europeos han ido incorporando sus preceptos bien en leyes específicas, bien en leyes sectoriales con apartados dedicados al paisaje" (Martínez y Molinero, 2019).

En España, el CEP se ratificó en noviembre de 2007, entrando en vigor en marzo de 2008, lo que ha determinado que "la definición contenida en el CEP haya pasado a formar parte de nuestro ordenamiento jurídico interno a partir de esa fecha, debiendo aceptarla, por tanto, como concepto legal vigente y que de acuerdo con nuestro actual sistema de fuentes, por el principio de jerarquía normativa, se sitúa por encima de cualesquiera otras disposiciones contenidas en otras legislaciones estatales o autonómicas" (Durán, 2011).

Pero las transferencias del Estado en materia de medio ambiente y ordenación del territorio a las comunidades autónomas justifican que la mayor parte de las iniciativas de ordenamiento jurídico desarrollado para cumplir con el CEP tenga este marco administrativo. Como en otros muchos aspectos, las diferentes sensibilidades e intereses han dibujado un panorama sumamente heterogéneo. Así, la tarea desarrollada por el Observatori del Paisatge (catálogos del paisaje, criterios de calidad paisajística, etc.) y el marco jurídico de la Ley 8/2005, de Protección, Gestión y Ordenación del Paisaje, han hecho de Cataluña la comunidad de referencia en materia de paisaje durante todo este tiempo, por más que, en materia legislativa, fuera precedida por la pionera legislación sobre el particular de la Comunidad Valenciana (Ley 4/2004, de 30 de junio, de Ordenación del Territorio y Ordenación del Paisaje). Asimismo, el 7 de Julio de 2008, Galicia aprobaba la Ley 7/2008, de 7 de julio de Protección del Paisaje de Galicia. Por último, el Decreto 90/2014 regulaba la Protección, Gestión y Ordenación del Paisaje en Euskadi; la Ley 4/2014 hacía lo propio en Cantabria, y en 2017 se aprobaba el anteproyecto Ley de Ordenación del Territorio y Paisaje de Castilla-La Mancha. Cuando esto no ha ocurrido, el proceder ha pasado por la elaboración de estrategias (Andalucía), directrices (Canarias) o atlas, cartas y mapas de paisaje (Murcia, Aragón, Rioja...). En todos los casos se reconoce el valor del paisaje y se promueven políticas para su conservación, ordenación y gestión, sirviendo de referencia a la planificación territorial y sectorial (Vadrí, 2018).

En otras comunidades, en cambio, la consideración del paisaje aparece dispersa en distintos documentos normativos y de planificación, en muchos casos como mera cláusula de estilo, y apenas ha tenido repercusión social o ha sido muy vaga: Castilla y León es un ejemplo expresivo. 


\section{IDENTIDAD TERRITORIAL Y PAISAJE EN CASTILLA Y LEÓN}

Pese a tener reconocidas las competencias estatutarias "sobre protección del medio ambiente y del paisaje, con especial atención al desarrollo de políticas que contribuyan a mitigar el cambio climático"1, la "altura" del debate en el ámbito político sobre la necesidad de avanzar en un conocimiento y caracterización del paisaje no ha sido precisamente ejemplar. Los Diarios de Sesiones de las Cortes de Castilla y León dejan testimonios elocuentes que pueden explicar las razones de esta desatención.

En efecto, como de hecho había ocurrido en otras comunidades, la entrada en vigor del CEP generó una inquietud no solo por trasladar sus principios al ordenamiento jurídico, reconociendo los paisajes "como elemento fundamental del entorno humano, expresión de la diversidad de su patrimonio común cultural y natural y como fundamento de su identidad" (art. 5.a), o por cumplir con sus requerimientos en relación a las políticas de "protección, gestión y ordenación" (art. 5.b) del paisaje, sino por dar cumplimiento a la tarea de reconocer, identificar y caracterizar el paisaje. Es este contexto, en la sesión de 10 de febrero de 2011 (tres años después de su entrada en vigor en España) se presentó la propuesta de resolución para que desde las Cortes se instara a la Junta de Castilla y León a elaborar un "catálogo del paisaje por cada una de las provincias de la Comunidad, recogiendo los distintos paisajes de la Comunidad, a fin de que sirvan de guía a la hora de llevar a cabo actuaciones para su protección y ordenación" (CCL. DS, 2011: 12501-12513). Propuesta que no prosperó al entender el grupo político que lleva gestionando la comunidad desde 1987 que "...conocemos el paisaje en el que nos movemos, aunque no tengamos el catálogo y el instrumento que usted propone", y que es innecesario porque los principios del CEP están recogidos "en otros instrumentos que permiten conocer y proteger los distintos paisajes de la Comunidad. Y estos instrumentos, pues, son, lógicamente, los de ordenación del territorio y son, lógicamente, los correspondientes a evaluación de impacto ambiental, que, como sabe, pues, refieren a prácticamente cualquier obra de cierta entidad que se realiza en nuestra Comunidad Autónoma”. Si a esto le agregamos que se cita el Atlas de los Paisajes de España (Mata y Sanz, 2004) como documento acabado y suficiente para completar esta tarea, no es de extrañar que se entienda innecesaria tal empresa: "Consideramos que ese trabajo, quizás, no tenga la sistemática de un catálogo, pero el paisaje de Castilla y León está perfectamente conocido en los distintos instrumentos de ordenación, $y$, por tanto, consideramos que no es necesario, que generaría duplicidades con los instrumentos propios realizados en esta Comunidad y también con ese Atlas nacional del paisaje" (CCL.DS, 2011: 12505).

1 Estatuto de Autonomía de Castilla y León. Artículo 70. G. 35. 
Esta disposición de las Cortes de Castilla y León es fiel reflejo de la incomprensión y del escaso eco que la traslación de los principios del CEP ha tenido en su consideración normativa, circunscribiéndose, a falta de un tratamiento integral, a materias de urbanismo y ordenación del territorio, por un lado, y al ámbito del medio ambiente y patrimonio histórico, por otro.

EL PAISAJE EN EL MARCO DE LA LEGISLACIÓN URBANÍSTICA Y DE LA ORDENACIÓN DEL TERRITORIO EN CASTILLA Y LEÓN

Resulta significativo constatar que en la Ley de Urbanismo de 1999 (Ley 5/1999, de 8 de abril), que tenía por objeto regular la actividad urbanística en la Comunidad de Castilla y León, el paisaje solo aparece cuando se considera el deber de que, en los diferentes usos del suelo, particularmente su urbanización y edificación, se procure una adaptación a su "ambiente". De esta forma, el paisaje se entiende como un entorno; pero un entorno positivo y, por ello, los deberes adaptativos son especialmente subrayados en los ámbitos de manifiestos valores naturales y culturales, particularmente en los bordes de los Espacios Naturales Protegidos (ENP) y de los Bienes de Interés Cultural (BIC) (art.9.b). Una idea que se repite al considerarlo nuevamente en las categorías de suelo rústico en términos de "entorno que se ha de preservar". Tiene, en suma, un "sentido positivo", el de un valor que hay que preservar, precisamente para asegurar el valor del objeto de intervención considerado digno de ser protegido, pero no desde una consideración del paisaje per sé, sino meramente escénica, lo que explica su ajustada atención en los Planes de Especial Protección (art.48). Por otro lado, la nueva redacción dada por la Ley de Medidas sobre Urbanismo y Suelo (Ley 4/2008, de 15 de septiembre), cuando el CEP ya ha entrado en vigor, apenas introduce avances en este sentido, si bien el paisaje se contempla como un ente con valor en sí mismo cuando se habla de que, entre los objetivos de la actividad urbanística pública, se encuentra "la protección del medio rural, incluida la preservación y puesta en valor del suelo rústico, los paisajes de interés cultural e histórico, el patrimonio etnológico y las formas tradicionales de ocupación humana del territorio" (art. 10). Más llamativa resulta la escasa alusión al paisaje cuando la ordenación trasciende el ámbito de lo urbano, afectando al territorio en su complejidad. Tal sucede en la Ley 10/1998, de 5 de diciembre, de Ordenación del Territorio de la Comunidad de Castilla y León, donde no se encuentra ninguna referencia al paisaje; como tampoco se hace en las leyes que posteriormente la modifican (Ley 14/2006, Ley 3/2010 y Ley 1/2013).

$\mathrm{Y}$ no es que en esta materia hayan faltado antecedentes y ejemplos de lo que el paisaje podría aportar en la ordenación del territorio. El caso de las Directrices de Ordenación de Ámbito Subregional de Valladolid y Entorno, DOTVAENT, aprobadas en 2001, es bien elocuente en este sentido. En este documento, el paisaje se considera una herramienta operativa fundamental 
en la gestión del territorio ("La calidad como objetivo y el paisaje como argumento" - Santos, 2003-) al definir ámbitos relativamente homogéneos de paisaje denominados "Unidades Paisajísticas" (U.P.), con el objetivo de moderar los impactos de la urbanización sobre los mismos. La urbanización, se señala, "no debe hacerse a costa u obviando las condiciones peculiares de los espacios valiosos (relieve, vegetación, orientación, sistema del agua), amenazados hasta ahora por acciones de parcelación y edificación ilegal o insensible" (DOTVAENT, 1998: 13). Son, por tanto, "marcos de referencia para las acciones de mejora del paisaje y para el control de su transformación" (DOTVAENT, 1998: 40). Pero, sobre todo, el paisaje aparece como una pieza clave en la protección de espacios singulares y considerados de alto valor ante lo que en el diagnóstico territorial se considera "agresiones ambientales y paisajísticas persistentes, que podrían tener su origen en la minusvaloración del paisaje y del territorio circundante" (DOTVAENT, 1998: 9). Esta cuestión es especialmente evidente en el caso de los paisajes rurales, y particularmente agrarios, al entender que "la ordenación de los usos agrarios se relaciona estrechamente tanto con la planificación territorial como con la conservación de los valores naturales. La agricultura modela, diversifica y enriquece el paisaje, protege el medio ambiente en función de su aporte material y energético al ecosistema, y puede ser también una actividad recreativa y educativa". Conscientes de la identidad histórica de estas formaciones, se establece "un ámbito de protección de las "Áreas de interés Paisajístico, Histórico y Agrícola” (A.P.H.A.) seleccionadas por la concurrencia de varios factores: suelos valiosos para el cultivo, diversidad y riqueza ecológica, calidad visual y existencia de estructuras agrarias históricas con valor patrimonial y paisajístico" (DOTVAENT, 1998: 20).

Obviamente, a los redactores de las DOTVAENT no les resultaban desconocidos los preceptos teóricos del CEP, pero hubo que esperar a la misma fecha de su entrada en vigor en España para que, en Castilla y León, se hiciera referencia expresa al paisaje en una ley que no concierne a los ámbitos naturales. Concretamente la Ley 3/2008 por la que se aprueban las Directrices Esenciales de Ordenación del Territorio. En ella, al referirse al patrimonio rural, paisajes culturales y bienes culturales intangibles, se señala explícitamente que "las estrategias territoriales y locales en materia de patrimonio cultural reconocerán la riqueza de la cultura popular de la región, valorando el patrimonio intangible vinculado a paisajes y lugares y activando los recursos necesarios para la recuperación del patrimonio rural amenazado. Para ello, prevé crear una red de paisajes culturales que facilite el conocimiento y disfrute de los sistemas etnológicos que manifiestan modos históricos singulares de relación entre el hombre y el medio natural" (Cap. 3.10).

Así, el paisaje, resultado de esa relación secular entre el hombre y el medio, con sus rasgos formales y simbólicos, y sus valores "patrimoniales", se convierte en 
objeto de atención específica, evidenciando la creciente importancia de la cultura territorial y la dimensión territorial de la cultura. Pero no se alude al paisaje en el sentido que recoge el CEP, y lo que parece ser una puerta de entrada se revela pronto como un portillo cerrado. Resulta significativo que no se haga referencia al CEP en ningún punto de su articulado, a diferencia de lo que ocurrirá en documentos de ordenación de escala subregional. Tal sucede, por ejemplo, en el Decreto 21/2010, de 27 de mayo, por el que se aprueba el Plan Regional de Ámbito Territorial del Valle del Duero ${ }^{2}$. En este documento se hace referencia explícita al CEP. Concretamente, en su Título V "Protección y Desarrollo de los Paisajes del Duero", establece una consideración sistemática del concepto de paisaje y la instrumentación del mismo, como requiere el Convenio Europeo del Paisaje, a nivel de ordenación, gestión y ejecución. Para ello, el Plan se apoya en la definición de tres escalas de aproximación al territorio y sus correspondientes instrumentos para articular la colaboración público-privada o para la toma de decisiones. Una de estas escalas es la relativa a lo que el documento denomina "paisaje total", entendido a partir de las "Unidades Homogéneas de Gestión Paisajística” como ámbitos en los que se definen las grandes estrategias del paisaje. Una escala menor, y de carácter transversal, la proporcionan los "morfotipos del paisaje", que permiten una ordenación espacial coherente al coser distintos territorios y todos los Sistemas Territoriales. Y, finalmente, el último nivel lo forman las "áreas de interés paisajístico", un conjunto de paisajes valiosos, de interés ambiental, cultural, ecológico o natural y orientados a su especial protección; y de paisajes singulares o ámbitos de valor paisajístico con vocación de intervención. Todas ellas permiten una mejora global a través de la percepción positiva de un conjunto de intervenciones tanto de protección como de desarrollo. Por último, si en materia ambiental, se define el encaje entre el Plan y el planeamiento local, en materia de paisaje, se proponen un conjunto de instrumentos para el análisis, la ordenación, y la gestión del paisaje, como son los Objetivos de Calidad Paisajística, los Estudios de Paisaje o los Contratos del Paisaje, en previsión del desarrollo posterior.

Otro ejemplo lo podemos encontrar en el Decreto 34/2010, de 2 de septiembre, por el que se aprueba el Plan Regional de Ámbito Territorial Zamor@-Duero ${ }^{3}$, documento que incorpora algunas reflexiones y recomendaciones básicas de la Estrategia Española de Desarrollo Sostenible, de Medio Ambiente Urbano, de Movilidad Sostenible, de Cambio Climático y Energía Limpia y del Convenio Europeo del Paisaje, algunas de cuyas orientaciones se recogen en las propuestas

2 Decreto 21/2010, de 27 de mayo, por el que se aprueba el Plan Regional de Ámbito Territorial del Valle del Duero. BOCyL no 104, de 2 de junio de 2010.

3 Decreto 34/2010, de 2 de septiembre, por el que se aprueba el Plan Regional de Ámbito Territorial Zamor@-Duero. BOCyL no 174, de 8 de septiembre de 2010. 
de rango indicativo, incluidas para los sectores de desarrollo de las actuaciones, sus condiciones de urbanización y tratamiento de espacios libres, infraestructuras ambientales y de servicio.

Por último, en la Ley 4/2011, de 29 de marzo, de aprobación de las Directrices de Ordenación de Ámbito Subregional de la Montaña Cantábrica Central en Castilla y León ${ }^{4}$, el paisaje se analiza desde la descripción de sus componentes o elementos básicos; desde el análisis de los procesos que justifican las formas o los usos y las actividades que a lo largo del tiempo sobre ellas se dan, y desde el análisis de los impactos que estos elementos o procesos producen en el territorio. El análisis del paisaje se destaca como el instrumento más idóneo para valorar el sentido de la transformación del territorio, como indicador de calidad ambiental y como recurso económico. Como tal, es un elemento sustantivo en las aproximaciones hacia el diagnóstico del territorio y su ordenación. La protección de los valores naturales y culturales y el desarrollo sostenible sobre la base de los recursos territoriales disponibles se ha de apoyar en la gestión del paisaje y sus componentes, impactos y procesos. Por ello, el título V, que se refiere a las "Directrices sobre gestión paisajística", contiene determinaciones para proteger, ordenar y gestionar los paisajes y regular los principales usos y actividades en cada uno de ellos. Serán, por último, las características fisiográficas y paisajísticas del espacio objeto de ordenación, la base para la división en cinco Unidades de Gestión Paisajística: Alta Montańa, Montaña de León, Montaña de Palencia, Piedemonte y Las Loras.

Se podrían apuntar más ejemplos que abundarían en la misma idea. Desde la ordenación del territorio se consideran unos principios que la legislación general no recoge. La razón radica en que, en Castilla y León, y no es una excepción, ha sido en las ramas del derecho ambiental y del derecho protector del patrimonio histórico donde se han encontrado mayores desarrollos normativos en materia de protección del paisaje.

\section{EL PAISAJE EN EL MARCO DE LA PROTECCIÓN DEL PATRIMONIO HISTÓRICO}

$\mathrm{Si}$ tenemos presente el fuerte componente cultural del paisaje y subrayamos sus valores patrimoniales, hemos de comenzar señalando que la Administración de Castilla y León siempre se ha esforzado, a falta de otras seńas identitarias, en reconocer que "el patrimonio cultural forma parte de los valores esenciales y de la identidad de la Comunidad de Castilla y León”s. Es la razón por la que asumen

4 Ley 4/2011, de 29 de marzo, de aprobación de las Directrices de Ordenación de Ámbito Subregional de la Montańa Cantábrica Central en Castilla y León. BOCyL n ${ }^{\circ}$ 109, de 7 de mayo de 2011.

5 Junta de Castilla y León (2019). Patrimonio Cultural. Patrimonio y bienes culturales. Recuperado 21 de septiembre 2019 de http://patrimoniocultural.jcyl.es/web/jcyl/PatrimonioCultural/ es/Plantilla66y33/1284389003066/_/_/ 
que el patrimonio "es objeto de especial protección y apoyo; y, para estos fines, diversas entidades se ocupan de su tutela, conservación, fomento y gestión, y, a su vez, promueven programas de intervención y la participación y sensibilización social, dado que el patrimonio cultural es un legado común en cuya protección, valoración y activación debe participar el conjunto de la sociedad"6.

En este contexto, es necesario referirse a los pilares sobre los que se asienta la regulación normativa del patrimonio y de los bienes culturales: la Ley 12/2002, de 11 de julio, de Patrimonio Cultural de Castilla y León, y el Decreto 37/2007, de 19 de abril, por el que se aprueba el Reglamento para la Protección del Patrimonio Cultural de Castilla y León.

Por lo que al primer caso respecta, la Ley 12/2002, tiene como finalidad la protección, acrecentamiento y difusión del Patrimonio Cultural de Castilla y León, así como su investigación y transmisión a las generaciones futuras. En su artículo 8, define y clasifica este patrimonio en bienes muebles e inmuebles, y entre estos últimos se hace referencia a las siguientes categorías: monumento, jardín histórico, conjunto histórico, sitio histórico, zona arqueológica, conjunto etnológico y vía histórica. Pese al sesgo territorial de estos bienes, el paisaje no está presente. De hecho, solo se habla de paisaje a efectos de conservación en su artículo 42.2, cuando apunta que "la conservación de los sitios históricos y conjuntos etnológicos comporta el mantenimiento de los valores históricos, etnológicos, paleontológicos y antropológicos, el paisaje y las características generales de su ambiente". De igual forma lo trata el Reglamento de Protección, cuando, a la hora de tramitar los expedientes de declaración de un Bien de Interés Cultural y de Bienes Inventariados, contempla el paisaje en la delimitación del entorno, donde se pondera la protección y valoración estética, integrando el bien en el paisaje. Una consideración que reafirma la excepcionalidad del paisaje y, de nuevo, su entendimiento como un escenario, como un entorno, en el que hay que inscribir el bien.

Una visión que no se supera en el Anteproyecto de Ley de Patrimonio Cultural de Castilla y León, si bien se avanza de forma sustancial al explicitar, ahora sí, como una categoría más, la forma de Paisaje Patrimonial. Efectivamente, en el artículo 17, el paisaje aparece, en la relación de Bienes Inmuebles de Interés Cultural, junto a otras figuras consideradas "Áreas Patrimoniales", como los Conjuntos Históricos, los Sitios Históricos, las Zonas Arqueológicas, los Conjuntos Etnológicos, las Vías Históricas, y los Conjuntos Industriales. En este marco normativo, el Paisaje Patrimonial se define como un "espacio integrado por bienes culturales, tangibles e intangibles, vinculados directamente al territorio en el que se ubican, ya sea un área rural, urbana o mixta, en el que la combinación de los valores y del territorio configuran el carácter que identifica al paisaje como

6 Junta de Castilla y León (2019). Patrimonio Cultural. Patrimonio y bienes culturales... 
tal, y que constituye un ejemplo destacado de formas de asentamiento humano, sincrónico o diacrónico, o de utilización de bienes representativos de una comunidad". Una consideración cargada de abstracción y de difícil segregación de las figuras anteriores que presentará, de salir adelante el anteproyecto, no pocos problemas de identificación. Pero, llamativamente, tampoco se hace referencia al CEP, porque sus principios se han incorporado jurídicamente de la mano del derecho ambiental.

\section{EL PAISAJE EN EL MARCO DEL DERECHO AMBIENTAL DE CASTILLA Y LEÓN}

Como ha apuntado Velázquez, la entrada en vigor del CEP ha dado al paisaje un estatus de concepto legal vigente e independiente, susceptible de una regulación específica, circunstancia que marca una diferencia notable a la forma en la que se había tratado hasta ese momento, ya que, en general, "se ha venido enmarcando dentro de la gestión ambiental” (Velázquez, 2012). Es lo que ocurría en la Ley de Espacios Naturales de Castilla y León (Ley 8/91, de 10 de mayo) que, por otro lado, participaba de una visión "convencional" del paisaje: la que recurrentemente lo presenta limitado a su condición estética y singular. De ahí su consideración en las figuras de protección de mayor rango, como los Parques, donde "la belleza de sus paisajes" justificaría, junto a otros aspectos, una atención preferente. Incluso, se considera una categoría específica dentro de los Espacios Naturales Protegidos: los Paisajes Protegidos, definidos como "aquellas áreas del medio natural que, por sus valores estéticos y culturales, sean merecedores de una protección especial" (art. 16). En ese marco también se consideraba la tarea de elaborar "Normas de Protección y gestión que contendrán, al menos, la regulación de sus usos y el régimen de autorizaciones acordes con el Plan de Ordenación de los Recursos aprobados." (art. 29). El tratamiento del paisaje no difiere de lo que ha sido común en los distintos ámbitos administrativos, del autonómico al estatal. La cuestión es que, en Castilla y León, pese a que inicialmente se propusieron algunos paisajes para formar parte de la Red de Espacios Naturales (REN) en 1995, y dados los problemas de definición y gestión, esta figura nunca llegó a desarrollarse.

Sin embargo, la Ley 4/2015, de 24 de marzo, del Patrimonio Natural de Castilla y León, ha dado un paso decisivo en la vinculación del paisaje con el patrimonio natural pues, ahora, tras siete años de su entrada en vigor en España, incorpora al ordenamiento jurídico de Castilla y León los contenidos del Convenio Europeo del Paisaje. La Ley del Patrimonio Natural de Castilla y León es "la única ley que de momento incorpora al ordenamiento jurídico regional "los fundamentos necesarios para dar cumplimiento al Convenio Europeo del Paisaje" [...] remarcando que "la protección del paisaje se consigue también como consecuencia indirecta de la protección del patrimonio natural que constituye la esencia de esta ley". Esta puntualización es significativa, pues 
viene a justificar la presencia, algo forzada en una ley de patrimonio natural, de un articulado genérico referido al paisaje según los principios del CEP, por definición integradores, trasversales y generalistas.

Bien es cierto que el encuadramiento de un concepto (quizá solo una noción) como el paisaje en el marco de una ley de patrimonio natural, no es exclusivo, ni resulta tampoco extraño. Por un lado, se ha apuntado ya, es lo que se ha venido haciendo hasta ahora. Por otro, a escala nacional, la misma Ley del Patrimonio Natural y de la Biodiversidad (Ley 42/2007), aunque "en una interpretación sistemática podría deducirse que deja al paisaje deliberadamente fuera de la regulación básica del Patrimonio Natural y la Biodiversidad [...], sí lo considera, en cualquier caso, una parte del medio ambiente" (Durán, 2011).

Pero en Castilla y León esa integración se hace de forma muy particular. De hecho, en su Título II, que se refiere al paisaje, no lo define directamente, ni siquiera remite al artículo primero del CEP, sino que utiliza la definición contemplada en el artículo 3.26 de la Ley 42/2007. Tampoco hace referencia al CEP al asumir que la Junta de Castilla y León aprobará "la normativa necesaria para garantizar el reconocimiento, protección, gestión y ordenación del paisaje" (art. 15), aspectos recogidos entre los objetivos y medidas generales (art 3 y 5 ) del CEP. Significativo resulta igualmente que no se haga alusión a las medidas específicas, particularmente en lo tocante a la identificación y cualificación de los paisajes).

Por otro lado, los cinco artículos del Título II, superan con mucho lo dicho en el preámbulo. Así, se habla de "preservar los valores naturales, patrimoniales, culturales, sociales y económicos [del paisaje] en un marco de desarrollo sostenible" (Art.15), "de acuerdo con los conceptos de utilización racional del territorio, desarrollo urbanístico sostenible y funcionalidad de los ecosistemas" (Art.16). Es decir, el enfoque del articulado es, ciertamente, el tratamiento trasversal del paisaje, que requiere "la cooperación entre las diversas administraciones públicas en la elaboración y ejecución del planeamiento y de las políticas de paisaje" (Art. 16) siguiendo los criterios (aún por definir) "que regirán las actuaciones sectoriales que tengan incidencia sobre el mismo" (Art.19).

No obstante, el CEP, en su artículo 2, referido al ámbito de aplicación, indica que el "Convenio se aplicará a todo el territorio de las Partes y abarcará las áreas naturales, rurales, urbanas y periurbanas. Comprenderá asimismo las zonas terrestres, marítima y las aguas interiores. Se refiere tanto a los paisajes que puedan considerarse excepcionales como a los paisajes cotidianos o degradados". Sin embargo, la Ley de Patrimonio Natural enfatiza la dimensión de espacios sobresalientes, con la intención de elaborar un "Catálogo de Paisajes Sobresalientes de Castilla y León, en el que se recogerán aquellos territorios donde estén representados los distintos paisajes característicos de Castilla y León en buen estado de conservación", y que, "En base al mismo se analizará, para aquellos que 
no se encuentren incluidos en algún espacio natural protegido ya declarado, su posible declaración como Paisaje Protegido" (art. 18, 1 y 2). Figura esta que ahora se vuelve a considerar como una de las categorías de la REN.

En suma, el tratamiento jurídico del paisaje en Castilla y León ha limitado sustancialmente su potencial como herramienta de gestión integral del territorio, más allá de los bienes o conjuntos culturales considerados amparados por el paraguas del patrimonio cultural o de los espacios naturales protegidos en virtud de sus valores naturales. El reto se ha fijado en la identificación de los que tienen valores excepcionales. Paisajes protegidos previstos, de momento, solo en la Ley de Patrimonio Natural, pero también previsibles en la de Patrimonio Cultural a través de la figura de paisaje patrimonial. Tarea nada fácil en el contexto de una comunidad autónoma que no se singulariza precisamente por afrontar los problemas territoriales de manera integrada.

\section{LAS DIFICULTADES DE IDENTIFICACIÓN DEL PAISAJE}

Ya se ha hecho alusión a que el tratamiento del paisaje en Castilla y León evidencia la incomodidad que el reconocimiento, gestión, protección y ordenación paisaje supone para las administraciones, divididas en compartimentos de gestión sin mucha vocación de coordinarse. Ello representa un claro problema en este caso, dada la complejidad y transversalidad del paisaje con certeza de verse afectado por todas las políticas sectoriales con incidencia en el territorio.

Lo primero y más relevante es el hecho de que la ley elegida en la región para encajar los principios del CEP como una declaración de intenciones sea de patrimonio natural y no exista voluntad de desarrollar una normativa específica que preste atención propia y diferenciada al paisaje e implique a todas las actuaciones de gestión territorial dentro de la administración. En este sentido, llama la atención la diferencia con la legislación nacional, la Ley 42/2007, de 13 de diciembre, del Patrimonio Natural y de la Biodiversidad, donde la protección del paisaje "se afirma como uno de los principios de la presente ley y en ella se regulan aspectos puntuales de la política de paisaje [...] no pretende, sin embargo, la presente ley ser el instrumento a través del cual se implantarán en España, de manera generalizada, las políticas de protección del paisaje [...] políticas cuyo contenido técnico y enfoque general, no exento de valor paradigmático, exigen la puesta en marcha de instrumentos de gestión como los establecidos, con carácter de mínimos, en el Convenio Europeo del Paisaje” .

Ello no hace sino reforzar la incomprensión generalizada del paisaje como imagen totalizadora. Su vinculación, al menos nominal, con "lo natural" evoca la visión más clásica: la que atribuye al paisaje su condición de admirable en su aspecto estético-artístico, normalmente dominado por valores naturales. Una visión reduccionista y parcial, radicalmente contraria a los principios del CEP, entre los que destacamos la ausencia de adjetivación respecto del paisaje y la 
extensión del concepto paisaje a la totalidad del territorio (Art. 2. "Ámbito de aplicación" y Art.15. "Aplicación territorial").

Son los del Convenio Europeo del Paisaje unos planteamientos rupturistas respecto a los clásicos, que consideraban el paisaje solo vinculado con lugares singulares o excepcionales por sus atributos naturales o culturales. Pero, con gran frustración, observamos que tal enfoque único se mantiene y consolida y que, por el compromiso adquirido, la obligada referencia al paisaje en cada ley de nuevo cuño lo acentúa. Así se constata, también, en el Anteproyecto de Ley de Patrimonio Cultural de Castilla y León, a punto de ser aprobada. El documento solo incorpora el paisaje con apellido, esto es, como "paisaje patrimonial".

Es en este marco de desafección pública y parcialidad en la comprensión de los paisajes, con el consiguiente desatino a la hora de encarar su protección, gestión y ordenación, donde hay que enmarcar las propuestas para la identificación de paisajes patrimoniales o sobresalientes. La tarea resulta necesaria, pero en Castilla y León se parte de una carencia fundamental: no se han identificado ni caracterizado la totalidad de sus paisajes. Razón por la que resulta no solo procedente, sino necesario, abordar y resolver esta cuestión previa de identificar espacios cuyo paisaje responde a unas "magnitudes" patrimoniales homogéneas. Solo a partir de dichos paisajes se puede emprender, con mayores garantías, la selección de aquellos que resulten de interés patrimonial por su singularidad o porque sean los que mejor sinteticen y transmitan unos valores que la población reconozca y comparta.

\section{Consideraciones y PROPUeSTAS PARA LA IDENTIFICACión DE PAISAJES DE INTERÉS PATRIMONIAL EN CASTILLA Y LEÓN}

La falta de voluntad para desarrollar una normativa específica sobre reconocimiento y gestión del paisaje en Castilla y León ha derivado en una situación paradójica. Se están avanzando propuestas para la identificación de aquellos paisajes que se consideran excepcionales por sus valores naturales, culturales o mixtos (paisajes protegidos o paisajes sobresalientes, se denominan en la Ley de Patrimonio Natural; Paisajes Patrimoniales, en el Anteproyecto de la Ley de Patrimonio Cultural), sin haber analizado, tal como prevé el CEP, la diversidad paisajística de la región. Se entiende necesario en este contexto realizar una valoración propositiva que pasa, en primer lugar, por considerar la forma de conceptuar y la manera de proceder. 


\section{NOCIONES, CONCEPTOS Y PROCEDIMIENTOS.}

El interés creciente por los espacios de valor excepcional ha generado un amplio número de calificativos y figuras de protección tanto en el ámbito académico como normativo (Silva, 2016): paisajes culturales, zonas patrimoniales, paisajes de interés cultural, lugares de excepcional valor paisajístico, paisajes singulares y paisajes sobresalientes, entre otros ${ }^{7}$. De ellas, la que mayor proyección ha logrado es la de Paisaje Cultural, por ser la que utiliza la UNESCO para incluir determinados espacios en su Lista del Patrimonio Mundial. Aunque, como señalan Silva, Fernández y Mata (2018: 21), no es la denominación que se considera más acertada (dado que todos los paisajes son culturales), el hecho de ser la forma de referirse a una figura institucionalmente reconocida obliga en cualquier propuesta a utilizarla de manera cauta. La definición de los conceptos de Paisaje y Paisaje Cultural conduce en ocasiones a poco fructíferas discusiones en torno a la necesidad de incorporar el epíteto "cultural" (IAPH, 2015: 5), y aunque ahondar en ello no es objeto del presente artículo, sí conviene matizar ciertas cuestiones que argumenten los conceptos utilizados en la propuesta para Castilla y León.

Si comparamos la definición de Paisaje Cultural de la UNESCO con la definición de paisaje del CEP, enseguida se aprecia el planteamiento más abierto de esta última, al incluir las dimensiones perceptiva y vivencial. Por esta razón, la definición de Paisaje Cultural recogida por el Plan Nacional de Paisaje Cultural de $2012^{8}$, parece más acertada para el caso que nos ocupa, pues integra el núcleo de la que en 1992 hizo la UNESCO y le añade además dos aspectos clave de la definición de paisaje que proporciona el CEP: (i) el hecho de que el paisaje es una cualidad de cualquier territorio (sin el atributo de la excepcionalidad) y (ii) que el paisaje implica percepción.

Por otro lado, la Ley 42/2007, de 13 de diciembre, del Patrimonio Natural y de la Biodiversidad, incorpora un "instrumento explícito para la ordenación de los recursos paisajísticos, denominados Paisajes Protegidos” (Velázquez, 2012: 8).

7 "En España se produce un temprano reconocimiento de este tipo de paisajes, pues el Instituto Nacional para la Conservación de la Naturaleza (ICONA) realizó un primer Inventario de Paisajes Sobresalientes en 1975. Posteriormente este inventario sirvió de base para el reconocimiento de un buen número de paisajes por parte de las comunidades autónomas". Silva, R., Fernández, V. y Mata, R. (2018). Concepto, ámbito y significado de los paisajes patrimoniales. En F. Molinero y J. Tort (Coords.), Paisajes patrimoniales de España (pp. 17-40). Madrid: Ministerio de Agricultura, Pesca y Alimentación, Ministerio para la Transición Ecológica y UAM Ediciones.

8 "Paisaje cultural es el resultado de la interacción en el tiempo de las personas y el medio natural, cuya expresión es un territorio percibido y valorado por sus cualidades culturales, producto de un proceso y soporte de la identidad de una comunidad". Instituto de Patrimonio Cultural de España (2012). Plan Nacional de Paisaje Cultural. Madrid: Ministerio de Educación, Cultura y Deporte. Recuperado el 29 de septiembre de 2019 de https://sede.educacion.gob.es/publiventa/ descarga.action?f_codigo_agc=15113C 
Figura ya contemplada en la Ley 4/1989, de Conservación de Espacios Naturales y de la Flora y Fauna Silvestre, si bien ahora se enfatiza "la relevancia de los paisajes en función de sus valores naturales, estéticos y culturales y de acuerdo con el Convenio Europeo del Paisaje", siendo los motivos de protección "la conservación de sus valores y la preservación de la interacción entre la naturaleza y la cultura" (Velázquez, 2012: 8). En esta figura se basa la protección paisajística en comunidades autónomas como Asturias, Aragón, Navarra, Extremadura o Andalucía. También Castilla y León, si bien, como se ha indicado, no se ha desarrollado.

En todo caso, conviene tener presente la idea expresada por Fernández y Silva (2015): "El concepto de paisaje implica siempre mirada humana; es decir, la imagen procesada por un cerebro influido por claves culturales; incluso aunque esta mirada se dirija a un espacio natural no intervenido. Así, hablar de paisaje natural es una incongruencia, lo mismo que decir paisaje cultural es una redundancia”.

Por tanto, en esta propuesta para el estudio paisajístico de Castilla y León consideramos que se debe adoptar, desde el punto de vista conceptual, el término "paisaje" para abordar la tarea inicial de identificarlos y caracterizarlos en todo el territorio regional. Abundando más en esta cuestión, parece razonable incorporar términos que ya están presentes en otras comunidades autónomas, como "demarcaciones paisajísticas", a semejanza de los trabajos metodológicos del Instituto Andaluz del Patrimonio Histórico (IAPH) (Fernández et al., 2010). La "demarcación paisajística”, a escala regional para Castilla y León se aproxima a la realidad territorial de la comarca, y como en Andalucía (Fernández et al., 2010) (y también en Asturias -Fernández, 2013: 136-) se justificaría con el fin de crear "comunes denominaciones en la taxonomía y conceptualización de los estudios sobre estos paisajes" (Fernández, 2013: 133). Las demarcaciones se asignan en ambas comunidades autónomas a territorios que "desde el punto de vista cultural, comparten características y rasgos en la escala de trabajo subregional [...]. [Las demarcaciones son] producto de la historia del territorio y de sus actividades que en ocasiones han estado y siguen estando en la base de su identidad" (Fernández et al., 2010: 15).

Reservamos la denominación "paisajes de interés patrimonial" para aquellos que, en el marco de los primeros, reúnan valores excepcionales socialmente reconocidos. Serían espacios acotados y relacionados, al menos, con una dominante patrimonial que les otorga carácter y en los que "la conjunción de valores naturales y culturales hace recomendable implementar instrumentos de fomento y/o protección" (Fernández et al., 2010: 21) siguiendo la terminología del CEP. En este sentido, asumimos el carácter cultural de los paisajes, incluso cuando sus valores sean naturales, ya que la propia definición de paisajes protegidos de la ley de Patrimonio Natural abunda en su condición cultural. 
A partir del método aportado por Rodrigo Cámara (Rodrigo et al., 2012), se pueden identificar varias categorías que originan paisajes de interés patrimonial: sistemas de asentamiento, sistemas de infraestructuras territoriales, sistemas de producción, sistemas de creencias, referentes naturales connotados ${ }^{9}$. Valdría, a nuestro entender, desarrollar estas grandes categorías para incluir los paisajes sobresalientes contemplados en la ley de Patrimonio Natural.

Las demarcaciones paisajísticas y los paisajes de interés patrimonial como escalas de referencia se identificarían en dos fases sucesivas, acordes con las recomendaciones metodológicas del Plan Nacional de Paisajes Culturales: (i) la caracterización de los paisajes en Castilla y León y (ii) el registro de los paisajes de interés patrimonial.

Esta cuestión nos lleva a considerar, en segundo lugar, que no se parte de cero. Todo lo contrario, se han ensayado múltiples procedimientos y métodos para identificar el carácter del paisaje y los valores patrimoniales del territorio. Los estudios que se desarrollan en el Laboratorio del Paisaje del IAPH y en el Centro de Estudios Paisaje y Territorio para Andalucía, son un referente claro para la presente propuesta de Castilla y León.

Dada la complejidad y dispersión territorial de las entidades consideradas bienes culturales, el texto referido, subraya la procedencia de analizar los valores culturales del paisaje en su conjunto, y no solo de aquellos considerados singulares (IPCE, 2012: 29). Es ahí donde identificamos como necesario, en primer lugar, un estudio a escala regional que permita identificar espacios cuyo paisaje responde a unas "magnitudes" patrimoniales homogéneas (Fernández, 2013: 133), del que resultarían las demarcaciones paisajísticas. Conocidos los procesos históricos, los recursos patrimoniales, la imagen proyectada y otros atributos de cada paisaje se seleccionará "aquella parte del territorio donde mejor se sinteticen, transmitan y sean reconocidos por la población" (IAPH), es decir, los paisajes de interés patrimonial objeto de registro.

Y es que la caracterización del paisaje aporta el marco de coherencia patrimonial necesario para el consiguiente registro de paisajes de interés patrimonial en Castilla y León. Partiendo de esta premisa y con el objeto de dar cumplimiento al $\mathrm{CEP}^{10}$ y al Plan Nacional de Paisaje Cultural ${ }^{11}$ la propuesta del registro de paisajes de interés patrimonial en Castilla y León se estructuraría así en dos fases:

9 Síntesis y adaptación de la propuesta conceptual de paisajes de interés cultural de Rodrigo Cámara y otros (2012) elaborada y publicada por Fernández Salinas (2013) para la Clasificación de Paisajes de Interés Cultural de Asturias.

10 "Promover la protección, gestión y ordenación de los paisajes". Art. 3 del Convenio Europeo del Paisaje.

11 Realizar una "identificación, caracterización y salvaguarda" de los paisajes de interés cultural (PIC), con orden y precisión. 2.3 Objetivos del Plan Nacional de Paisajes Culturales. 
1. Caracterización de los paisajes en Castilla y León. Esta fase supone un ejercicio de reintegración de las diferentes estructuras territoriales que nos permitan definir el carácter de cada paisaje en la escala de la demarcación paisajística.

2. Registro de paisajes de interés patrimonial en Castilla y León. Esta fase permite velar por la salvaguarda y la promoción de una mínima gestión de los paisajes, seleccionados no solo por su excepcionalidad sino también por ser un buen modelo del tipo de paisaje al que pertenecen o representan.

\section{DE LA CARACTERIZACIÓN DEL PAISAJE AL ESTUDIO DE LOS ATRIBUTOS PATRIMONIALES}

Solo partiendo de una caracterización de los paisajes en Castilla y León se podrá emprender con mayores garantías la identificación, selección y posterior registro de paisajes de interés patrimonial, que se deberán seleccionar en función de criterios de representatividad, integridad y singularidad, y donde se les reconozca un alto contenido patrimonial. Este ejercicio implica "ir más allá del carácter" de los paisajes previamente identificados y caracterizados, para abordar los atributos patrimoniales que se centrarán preferentemente en aquellos territorios que mejor representen y transmitan el carácter del paisaje, representativos, en suma, del tipo de paisaje al que pertenecen o representan. La propuesta para Castilla y León, apoyada en la localización y caracterización de los atributos patrimoniales, permitiría distinguir áreas de distinta intensidad, densidad y diversidad patrimonial, un procedimiento que según Silva y Fernández (2017) tiene un doble interés: analítico y prospectivo. Nos permite dar respuesta con posterioridad a "qué proteger en los paisajes" y "dónde hacerlo", aportando algunas claves sobre en qué aspectos debería recaer la protección, la ordenación y la gestión de los paisajes a los que alude el CEP.

El carácter es un término central en la labor de identificación y estudio de los paisajes a todas las escalas. La Countryside Agency and Scottish Natural Heritage publicó una guía para la evaluación del carácter paisajístico, un avance metodológico en el estudio de los paisajes comúnmente conocido como Landscape Character Assessment (LCA) (Swanwick, 2002). El documento publicado ha servido de método en catálogos y atlas de paisajes (Mata y Sanz, 2004) y otros estudios paisajísticos (Gómez, y Riesco, 2010) no solo en Espańa, sino en buena parte de Europa.

El carácter es definido por este método como "un patrón distintivo, reconocible y consistente de elementos en el paisaje que hace que un paisaje sea diferente de otro, en lugar de ser mejor o peor" (Swanwick, 2002: 9); resultante de la combinación, única e irrepetible en cada paisaje de a) un medio físico; b) unos procesos de construcción histórica y c) unas percepciones y representaciones sociales que remiten a su condición subjetiva y valorativa (Silva, Fernández y Mata, 2017: 22). 


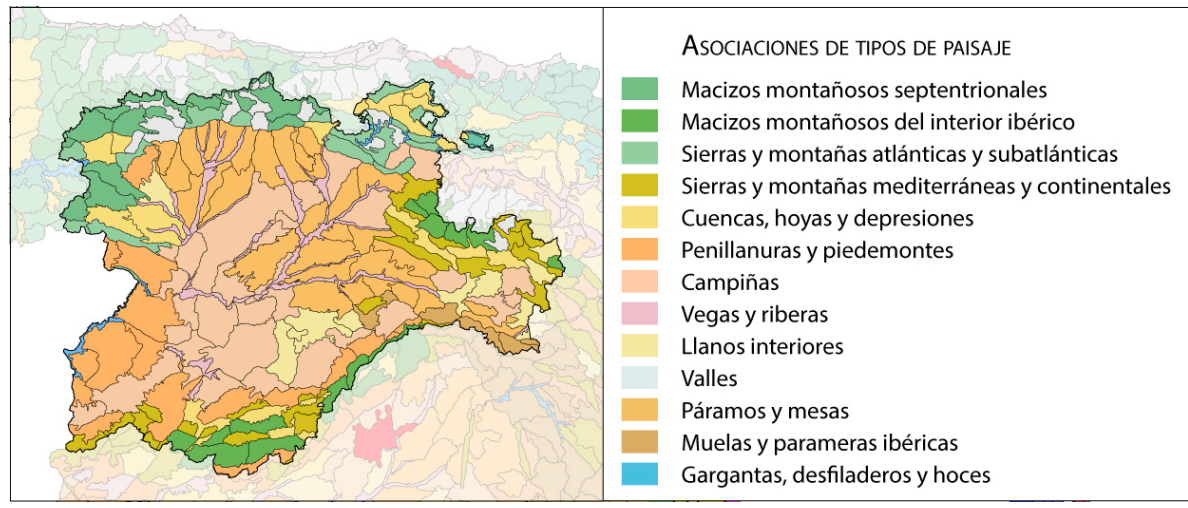

Figura 1. Fragmento del mapa de Asociaciones de tipos de paisaje del Atlas de los Paisajes de Espańa (Mata y Sanz, 2004).

El método LCA permite dar respuesta a las orientaciones que establece el CEP, cuya consecución implica un análisis del paisaje en las dimensiones morfológica, histórica, cultural y natural, y de sus interrelaciones, así como un análisis de las transformaciones. La percepción del paisaje por las poblaciones que participan es analizada, desde el punto de vista tanto de su desarrollo histórico como de su significado reciente, plasmada en una imagen proyectada concreta.

Si retomamos la discusión de las Cortes de Castilla y León anteriormente referida, podríamos señalar que una buena base de partida para esta fase de caracterización de los paisajes es el Atlas de los Paisajes de Espańa (Mata y Sanz 2004), pues reproduce la imagen física de los grandes ámbitos paisajísticos, con sus formas más evidentes y los rasgos climáticos e hidrogeográficos fundamentales. La caracterización puede considerarse "parcialmente" satisfecha por la conveniencia de redibujar las unidades expuestas en esta obra, de orientación fundamentalmente física, para matizar y caracterizar el paisaje desde una dimensión cultural y patrimonial. Gómez Zotano y Riesco Chueca señalan que las comunidades autónomas que han iniciado actividades descriptivas del paisaje superan o "van más allá del proceso iniciado en el Atlas" (Gómez y Riesco, 2010: 27-28), tanto en lo que se refiere a nivel de desglose (paisajes, en tipos y áreas, de menor extensión) como al grado de ambición otorgado a las caracterizaciones de cada paisaje. Por otro lado, son numerosas las iniciativas independientes de clasificación de paisajes espańoles, en ámbitos parciales o en la totalidad del territorio, con arreglo a diferentes criterios (García, Bolaños y Elena-Roselló, 2003; García-Feced, González-Ávila y Elena-Rosselló, 2008; Blanco, 1979; Gómez, 1999; Díaz Bea, 2000; Moniz et al., 2005; Gómez y Riesco, 2010: 28). Queda así argumentada la necesidad de redibujar, matizar y caracterizar desde el punto de vista cultural y patrimonial las unidades delimitadas en el Atlas de los Paisajes de España para Castilla y León. Se trata de una labor que otras comunidades autónomas han 
realizado en la fase inicial de caracterización del paisaje, con la diferencia de que partían de trabajos más recientes y detallados al circunscribirse a la escala regional, como el Mapa de Paisajes de Andalucía (Moniz et al. 2005) o los trabajos de Fernández, Herrán y González, 2010a y 2010b) para Asturias. Pero la lista de catálogos y atlas es muy amplia.

De la primera fase de caracterización resulta un documento de cómoda lectura y consulta, y constituye un medio útil para la sensibilización social del paisaje y contextualización de los diferentes paisajes patrimoniales que se desarrollan en la segunda fase.

\section{DEMARCACIÓN DE PAISAJE}

- Identificación y localización

3 El territorio

(-) Procesos históricos y actividades socioeconómicas

Recursos patrimoniales

La imagen proyectada

PIP Paisajes de Interés Patrimonial

Valoraciones y recomendaciones

Anexo cartográfico

(DD) Bibliografía

Figura 2. Propuesta de estructura del documento de caracterización para cada demarcación de paisaje. Fuente: Elaboración de D. Herrero Luque a partir de Fernández Cacho y otros, 2010, p. 19.

\section{UN REGISTRO DE PAISAJES DE INTERÉS PATRIMONIAL EN CASTILLA Y LEÓN}

El epígrafe sexto del esquema propuesto para el documento de cada demarcación paisajística (Figura 2) recoge los paisajes de interés patrimonial de los que ha de partir la segunda fase, centrada en su catalogación. La propuesta del Registro de Paisajes de Interés Patrimonial (RPIP) en Castilla y León toma como modelo el RPIC de Andalucía. Pretendería, como aquella, erigirse como un cuerpo de datos homogéneo y normalizado, "sin efectos jurídicos sobre el territorio o los bienes culturales analizados, que recoge una completa y diversa información sobre una serie de áreas territoriales que han sido seleccionadas por ser depositarias de una serie de valores patrimoniales, culturales e históricos, que han participado y son testigos actuales de su formación como un paisaje cultural reconocible, significativo e identitario" (CCYPH.JA). La ejecución de la segunda fase ha de abordar las siguientes cuestiones. 


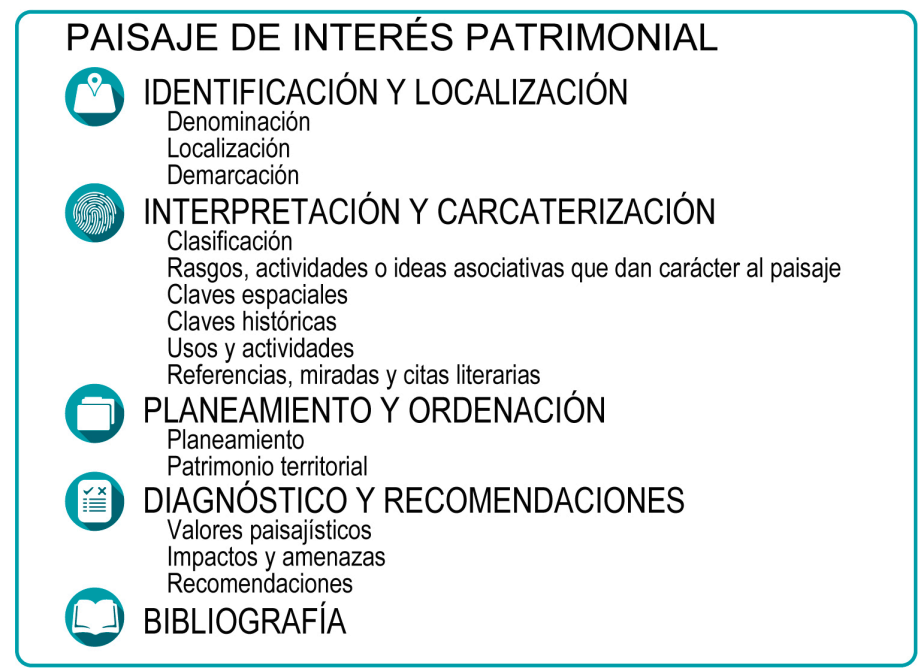

Figura 3. Estructura del documento de registro elaborado para cada Paisaje de Interés Patrimonial. Fuente: Elaboración de D. Herrero Luque a partir del Registro de Paisajes de Interés Cultural de Andalucía del Instituto Andaluz del Patrimonio Histórico.

Por otro lado, la elaboración del Registro de Paisajes Patrimoniales en Castilla y León requiere la participación de todos los agentes sociales y técnicos de diferentes disciplinas, con el fin de poder abarcar la totalidad del territorio autonómico desde todas las perspectivas valorativas y sensibilidades, y elaborar así un registro homogéneo -en términos de criterios de selección, categorización, etc.-, pues los atributos patrimoniales que definen los paisajes patrimoniales de Castilla y León son diversos, lo que requiere el entendimiento de expertos de diferentes materias y la colaboración permanente de la administración autonómica.

RESULTADOS ESPERADOS DE LA CARACTERIZACIÓN DE LOS PAISAJES Y DEL

\section{Registro de Paisajes Patrimoniales en Castilla y León}

A partir del procedimiento de caracterización esbozado, no resultaría difícil identificar, en primer lugar, las potencialidades de patrimonialización que posee el paisaje en cada demarcación. De ello devendría, en segundo lugar, una relación de aspectos que deberían ser consideradas en el planeamiento territorial para, por último, desarrollar una relación de paisajes de interés patrimonial, el registro propiamente dicho.

El registro de Paisajes Patrimoniales en Castilla, por otro lado, proporcionaría una síntesis de información referida a los valores patrimoniales de los paisajes de Castilla y León, de especial relevancia en futuras tareas didácticas y de sensibilización. También es un registro de especial interés para la planificación 
FASE 1 Identificación y caracterización de paisajes de Castilla y León

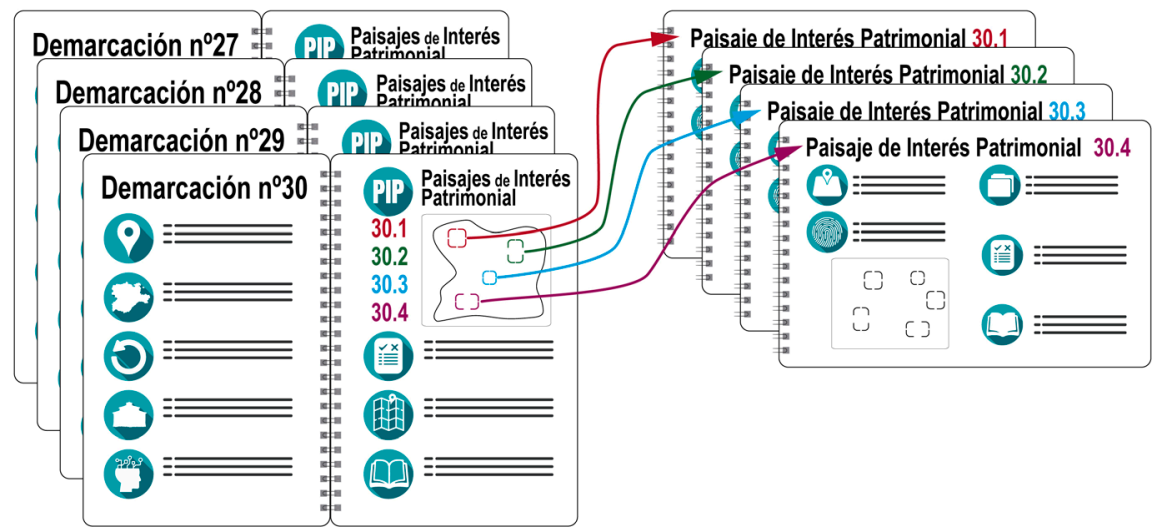

FASE 2 Registro de Paisajes de Interés Patrimonial de Castilla y León

aisaie de Interés Patrimonial 30.1

Paisaie de Interes Patrimonial 30.2

Paisaie de Interés Patrimonial 30.3
Paisaje de Interés Patrimonial 30.4

Figura 4. Esquema de la propuesta de proyecto sobre Paisajes de Interés Patrimonial de Castilla y León. Fuente: Elaboración de D. Herrero Luque.

territorial y facilitaría la disponibilidad de valoraciones y recomendaciones de cada paisaje de interés patrimonial de dimensión marcadamente territorial, claves para la toma de decisiones y el establecimiento de bases y criterios en términos de gestión y desarrollo territorial.

En todo caso, no son todo hipótesis, pues la administración regional está dando algunos pasos, si bien de forma ocasional y poco sistematizada. Desde la Consejería de Fomento y Medio Ambiente de Castilla y León apenas si trascienden actuaciones a la hora de identificar paisajes protegidos o sobresalientes desde la perspectiva de sus valores naturales. No ocurre lo mismo en la de Consejería de Cultura y Turismo, y más específicamente desde la Dirección General de Patrimonio Cultural. Además de la experiencia que proporciona la figura de Espacios Culturales para dos ámbitos singularísimos, con una clara expresión paisajística, incluidos en la Lista del Patrimonio Mundial (Las Médulas, en 1997, y Atapuerca, en 2000), algunos estudios específicos (Sayago, Aliste...) o más o menos elaborados, como los recogidos en la lista de los 100 paisajes culturales de España ${ }^{12}$ (con la intención de aproximarse a un registro similar al propuesto, pero a escala nacional), recientemente se ha licitado y se está elaborando el Libro Blanco y Catálogo de Enclaves Territoriales de Interés Cultural en Castilla y León.

Se trata del paso más importante dado hasta ahora en esta materia, y no deja de ser significativa la denominación escogida, pues elude, pese a sus claras

12 Incluye los siguientes paisajes de Castilla y León: Arribes del Duero, Paisaje agrario de la comarca de Sayago, Dehesas y casas-palacio de Ávila, Las Médulas, Salinas de Poza de la Sal, Canal de Castilla, Tiermes, Románico Norte, Las Batuecas y Sierra de Francia. 
analogías, el término paisaje. A falta del desarrollo de una figura específica en la Ley de Patrimonio Cultural, como la mencionada de Paisaje Patrimonial en el Anteproyecto de ley, se está elaborando una propuesta de 101 Enclaves Territoriales de Interés Cultural (ETIC), enmarcados dentro de la estrategia tendente a la protección del patrimonio cultural de Castilla y León a través de la catalogación de ámbitos de relevancia paisajística.

Los 101 ETCI se agrupan en grandes campos o categorías, en clara similitud con lo hecho en el Plan Nacional de Paisaje Cultural, o el propuesto para el caso andaluz anteriormente reseńado. Tales categorías o campos son: agrarios, extractivos, industriales, arqueológicos, urbanos, arquitectónicos y simbólicos. Dentro de ellos, se localizan, registran y catalogan los más relevantes, atendiendo a criterios de representatividad, significación territorial, singularidad, referenciación territorial, autenticidad, integridad, excepcionalidad, fragilidad/vulnerabilidad y viabilidad.

Asimismo, se prevé desarrollar mecanismos para la conservación: estrategias, pautas y acciones de protección; propuestas de gestión, conservación preventiva, sostenibilidad, coordinación de planes y actuaciones; propuestas de documentación, estudios y proyectos de investigación. Y, dentro de las políticas y actuaciones de intervención: criterios y elaboración de planes; directrices y propuestas de intervención en los enclaves; diseño de itinerarios y rutas; acciones de formación, participación y sensibilización social, fomento y difusión.

En suma, a falta de actualizar las nuevas sensibilidades en materia patrimonial en una ley renovada, que incluya las nuevas categorías (el paisaje entre ellas) y abunde no tanto en la protección como en la gestión integral y sostenible del patrimonio, el Libro Blanco constituye un anticipo de la tarea que se debe abordar. Sin embargo, lo esencial sigue estando sin resolver: la identificación y caracterización genérica e integral del paisaje en Castilla y León.

\section{Conclusiones}

La consideración integral del paisaje, tal y como se entiende en el Convenio Europeo del Paisaje, apenas si ha tenido un eco parcial y tardío en el marco normativo de Castilla y León. En el largo proceso de transposición legal de sus principios, se han ido quedando por el camino medidas específicas fundamentales (art. 6), como las que comprometen a la identificación de sus paisajes en todo el territorio; o las encaminadas a analizar sus rasgos, características y las fuerzas y presiones que los transforman; o las dirigidas a cualificarlos teniendo en cuenta sus valores, tanto reconocidos como vividos. En un contexto de falta de sensibilidad a todo lo que atañe a la cultura del territorio, se ha obviado lo esencial: el estudio de los paisajes cotidianos; de aquellos que, al margen de toda protección, son producto del normal aprovechamiento y ocupación del territorio; 
de su percepción y de su representación; aquellos en los que viven la mayor parte de los ciudadanos. En virtud de su variedad y extensión, la región del Duero alberga paisajes cotidianos miríficos en las vastas campiñas terracampinas; o en las llanuras labradas a distintos niveles en los páramos; o en los campos abiertos y ondulados de las planicies meridionales del Duero; o en los espacios ganaderos de las penillanuras salmantinas y zamoranas; o en las franjas fluviales de los ríos de la región. Pero, sobre todo, en la gran diversidad de paisajes de montańa, potenciados por ambientes climáticos muy contrastados. Son paisajes que evolucionan, que están vivos y expresan la organización del territorio en cada momento histórico. En muchos de ellos, su valor patrimonial es esencial, por lo que resulta aún más contradictoria su desatención en una comunidad autónoma que hace del patrimonio bandera y rasgo de identidad colectiva. Pero en los espacios cotidianos, en los que se desenvuelve la existencia del ciudadano común, donde se están produciendo las mayores transformaciones (instalaciones energéticas, tendidos eléctricos, infraestructuras de transporte, obras de modernización de regadíos, abandono y naturalización...) y donde resulta más legítimo apelar a la calidad de vida, el territorio se ve privado de una poderosa herramienta de comprensión y de ordenación: el paisaje.

\section{REFERENCIAS}

Blanco, A. A. (1979). La definición de unidades de paisaje y su clasificación en la provincia de Santander. Tesis doctoral, E.T.S. Ing. de Montes. Madrid: Universidad Politécnica de Madrid.

Consejería de Cultura y Patrimonio Histórico. Blog de la Consejería de Cultura y Patrimonio Histórico (CCYPH.JA). Registro de Paisajes de Interés Cultural de Andalucía. Junta de Andalucía. Recuperado el 1 de septiembre de 2019 de http://www.juntadeandalucia.es/cultura/blog/registro-de-paisajes-de-interescultural-de-andalucia-una-seleccion-de-paisajes-para-su-conocimiento-yvalorizacion-como-patrimonio-cultural/

Cortes de Castilla y León. Diario de Sesiones. (CCL.DS)(C) n. 649/7 del 10-22011, pp. 12501-12513. Recuperado 20 septiembre 2019 de http://sirdoc.ccyl. es/POCCYL/HTMPublicacion.asp?Leg=7\&Serie=DS(C)\&Numero=649

Davallon, J. (2006). Le don du patrimoine. Paris: Lavoisier.

Decreto 21/2010, de 27 de mayo, por el que se aprueba el Plan Regional de Ámbito Territorial del Valle del Duero. BOCyL no 104, de 2 de junio de 2010.

Decreto 34/2010, de 2 de septiembre, por el que se aprueba el Plan Regional de Ámbito Territorial Zamor@-Duero. BOCyL no 174, de 8 de septiembre de 2010. 
Díaz Bea, E. (2000). Clasificación, cartografía y valoración por los usuarios del paisaje de Álava meridional y propuestas de ordenación. Lurralde, 23, 181190.

Directrices de Ordenación del Territorio de Valladolid y su Entorno. DOTVAENT. Avance. 1998. Recuperado el 18 de septiembre de 2019 de https://iuu. uva.es/directrices-de-ordenacion-del-territorio-de-valladolid-y-entornoavance-1998/ En https://bop.sede.diputaciondevalladolid.es/boletines/2006/ febrero/01/ref_2006_391.pdf (p. 13).

Durán, J. L. (2011). Un nuevo concepto de paisaje. Recuperado el 20 de septiembre de 2019, de http://www.murciaenclaveambiental.es/segundotrimestre-2011.html?idRe=150\&iw4re=31

Estatuto de Autonomía de Castilla y León. Artículo 70. G. 35.

Fernández, F., Herrán, M. y González, J.A. (2010a). Los paisajes del litoral asturiano. En F. Leco Berrocal (ed.), Actas del XV Coloquio de Geografia Rural. Territorio, paisaje y patrimonio rural. (pp. 102-111). Cáceres: Grupo de Geografía Rural de la Asociación de Geógrafos Españoles.

Fernández, F., Herrán, M. y González, J. A. (2010b). Economía agraria y paisaje en la montańa asturiana. En F. Leco Berrocal (ed.). Actas del XV Coloquio de Geografía Rural. Territorio, paisaje y patrimonio rural. (pp. 112-119). Cáceres: Grupo de Geografía Rural de la Asociación de Geógrafos Españoles.

Fernández, S., Fernández, V., Hernández, E., López, E., Quintero, V., Rodrigo, J. M. y Zarza, D. (2010). Paisaje y Patrimonio Cultural en Andalucia. Tiempo, Usos e Imágenes. Sevilla: Instituto Andaluz del Patrimonio Histórico, Junta de Andalucía.

Fernández, V. (2013). Los paisajes de interés cultural de Asturias. Ería 91, 129149.

García, J. M., Bolaños, F. y Elena-Roselló, R. (2003). Clasificación de los paisajes rurales españoles según su composición espacial. Investigación agraria. Sistemas $y$ recursos forestales, 12 (3), 5-17.

García-Feced, C., González-Ávila, S. y Elena-Rosselló, R. (2008). Metodología para la tipificación y caracterización estructural de paisajes en comarcas forestales españolas. Investigación agraria. Sistemas y recursos forestales, 17 (2), $130-142$.

Gómez, J. (1999). Paisaje y espacios naturales protegidos en Espańa. Boletín de la Institución Libre de Enseñanza, II Época, 34-35, 130-152.

Gómez, J. y Riesco, R. (2010). Marco conceptual y metodológico para los paisajes españoles. Aplicación a tres escalas. Sevilla: Centro de Estudios de Paisaje y Territorio, Junta de Andalucía. 
Instituto Andaluz del Patrimonio Histórico (IAPH) (2015). Recomendaciones técnicas para la documentación de Paisajes de Interés Cultural. Consejería de Cultura y Deporte (p. 5). Recuperado 29 de septiembre 2019 de https:// repositorio.iaph.es/bitstream/11532/163070/5/RECOMENDACIONES_ DOC_PAISAJE_CULTURAL_2.pdf

Instituto de Patrimonio Cultural de España (IPCE) (2012). Plan Nacional de Paisaje Cultural. Madrid: Ministerio de Educación, Cultura y Deporte. Recuperado el 29 septiembre 2019 de https://sede.educacion.gob.es/ publiventa/descarga.action?f_codigo_agc $=15113 \mathrm{C}$

Juntade CastillayLeón (2019). Patrimonio Cultural. Patrimonioybienesculturales. Recuperado 21 de septiembre 2019 de http://patrimoniocultural.jcyl.es/web/ jcyl/PatrimonioCultural/es/Plantilla66y33/1284389003066/_/__

Ley 1/2013, de 28 de febrero, de modificación de la Ley 10/1998, de 5 de diciembre, de Ordenación del Territorio de la Comunidad de Castilla y León

Ley 3/2010, de 26 de marzo, de modificación de la Ley 10/1998, de 5 de diciembre, de Ordenación del Territorio de la Comunidad de Castilla y León.

Ley 4/2011, de 29 de marzo, de aprobación de las Directrices de Ordenación de Ámbito Subregional de la Montaña Cantábrica Central en Castilla y León. BOCyL. 109, 7 de mayo de 2011.

Martínez, M. y Molinero, F. (2019, en prensa). El valor patrimonial del paisaje como imagen de calidad en la estrategia comercial de los territorios vitivinícolas del Duero. Cuadernos Geográficos (n ${ }^{\circ}$ monográfico).

Mata, R. y Sanz, C. (Dirs.) (2004). Atlas de los paisajes de España. Madrid: Ministerio de Medio Ambiente, Centro de Publicaciones UAM.

Moniz, C., Moreira, J.M., Ojeda, J.F., Rodríguez, J., Venegas, C. y Zoido, F. (2005). Mapa de paisaje. En Junta de Andalucía, Atlas de Andalucía V. 2. Cartografía ambiental. Sevilla: Consejería de Obras Públicas y Transportes, Consejería de Medio Ambiente.

Ortega, J. (1998). El patrimonio territorial: El territorio como recurso cultural y económico. Ciudades. Revista del Instituto Universitario de Urbanistica de la Universidad de Valladolid, 4, 33-48.

Ortega, N. (2010). Nota Preliminar. Estudios Geográficos, 71, (269).

Rodrigo, J. M., Díaz, J. M., Fernández, S., Fernández, V., González, Hernández, E., López, E. y Quintero, V. Registro de Paisajes de Interés Cultural de Andalucía. Junta de Andalucía. Recuperado el 18 de septiembre de 2019 de http://www. juntadeandalucia.es/cultura/blog/registro-de-paisajes-de-interes-cultural-deandalucia-una-seleccion-de-paisajes-para-su-conocimiento-y-valorizacioncomo-patrimonio-cultural/ 
Santos, L. (2003). Las directrices de ordenación de ámbito subregional de Valladolid y su entorno. Un instrumento pionero de ordenación del territorio. En L. López, C. E. Relea y J. Somoza (Coords.), La ciudad: nuevos procesos, nuevas respuestas. Actas del VI Coloquio de Geografia Urbana (pp. 309317). León: Universidad de León, Secretariado de Publicaciones y Medios Audiovisuales.

Silva, R. (2016). Landscape, heritage and territory. Some notes from the Spanish geographic perspective. En Spanish Committee IGU, Crisis, globalization and social and territorial imbalances in Spain. Spanish Contribution to 33rd IGC Beijing 2016, pp. 54-62. Madrid: Asociación de Geógrafos Españoles, Instituto Geográfico Nacional y Gobierno de España. DOI 10.7419/162.02.2016.

Silva, R. y Fernández, V. (2017). El nuevo paradigma del patrimonio y su consideración con los paisajes: conceptos, métodos y prospectivas. Documents d'Anàlisi Geogràfica, 63 (1), 129-151.

Silva, R., Fernández, V. y Mata, R. (2018). Concepto, ámbito y significado de los paisajes patrimoniales. En F. Molinero y J. Tort (Coords.), Paisajes patrimoniales de España (pp. 17-40). Madrid: Ministerio de Agricultura, Pesca y Alimentación, Ministerio para la Transición Ecológica y UAM Ediciones.

Swanwick, C. (2002). Landscape Character Assessment, Guidance for England and Scotland. The Countryside Agency and Scottish Natural Heritage. Recuperado el 30 de agosto de 2019 de https://www.nature.scot/sites/default/ files/2018-02/Publication\%202002\%20-\%20Landscape\%20Character\%20 Assessment \%20guidance\%20for\%20England\%20and\%20Scotland.pdf

Vadrí, M. T. (2018). Aspectos jurídicos de los paisajes patrimoniales. En F. Molinero, y J. Tort (Coords.), Paisajes patrimoniales de España (pp. 39-66). Madrid: Ministerio de Agricultura, Pesca y Alimentación, Ministerio para la Transición Ecológica y UAM Ediciones.

Velázquez, J. (2012). Adecuación de la gestión paisajistica española al Convenio Europeo del Paisaje. Análisis de las adaptaciones normativas autonómicas y sus implicaciones prácticas sobre los paisajes ordinarios. Conama. Recuperado el 17 de septiembre de 2019 de http://www.conama1 1.vsf.es/conama10/download/ files/conama11/CT\%202010/1896707473.pdf

Zoido, F. (2009). El Convenio Europeo del Paisaje. En J. Busquets y A. Cortina (Coords.): Gestión del paisaje: Manual de protección, gestión y ordenación del paisaje (pp. 299-315). Barcelona: Ariel. 